\title{
Antipsychotic Medication and Risk of Incident Seizure in People with Autism Spectrum Disorder: Analyses with Cohort and Within Individual Study Designs
}

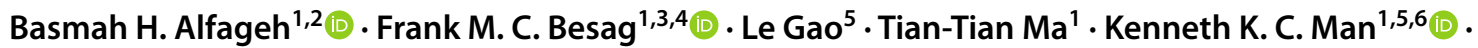 \\ lan C. K. Wong ${ }^{1,5}$ (D) Ruth Brauer ${ }^{1}$ (D)
}

Accepted: 19 July 2021 / Published online: 9 November 2021

(c) The Author(s) 2021

\begin{abstract}
There are many case reports of seizures apparently associated with the prescription of antipsychotics. This study aimed to examine whether there is an association between the prescription of antipsychotics and incident seizures in individuals with autism spectrum disorder using retrospective data based on patients' chart review. A cohort study was conducted to compare the rate of incident seizure between 3923 users of antipsychotics with 10,086 users of other psychotropics. This was followed by a self-controlled case series (SCCS) analysis of 149 patients to eliminate the effect of time-invariant confounders. The results showed no evidence of increased risk of seizure after exposure to antipsychotic agents (Hazard Ratio 1.28, 95\% CI 0.74-2.19) compared to other psychotropics.
\end{abstract}

Keywords Autism spectrum disorder (ASD) - Antipsychotic medication · Psychotropic medication · Incident seizure

\section{Introduction}

Autism spectrum disorder (ASD) is a neurodevelopmental disorder present at birth or beginning in early childhood (McPartland \& Volkmar, 2012). In 2016, the prevalence of ASD reached 1.6 per 100 children in the UK (Alfageh et al., 2020). There is no cure for ASD; however, psychotropic medications are used to manage the neuropsychiatric

Ruth Brauer

r.brauer@ucl.ac.uk

1 School of Pharmacy, University College London, London, UK

2 College of Pharmacy, King Saud University, Riyadh, Saudi Arabia

3 East London Foundation NHS Trust, Bedfordshire, UK

4 Institute of Psychiatry, Psychology and Neuroscience, King's College London, London, UK

5 Centre for Safe Medication Practice and Research, Department of Pharmacology and Pharmacy, Li Ka Shing Faculty of Medicine, The University of Hong Kong, Pokfulam, Hong Kong

6 Department of Medical Informatics, Erasmus University Medical Centre, Rotterdam, The Netherlands comorbidities that often accompany it (Hsia et al., 2014; Ji \& Findling, 2015; Wong et al., 2014).

Antipsychotics have commonly been used in the management of disruptive behaviours in individuals with ASD (Ji \& Findling, 2015; Posey et al., 2008). The efficacy of antipsychotics in the management of behavioural disorder associated with ASD has been reported in several randomised controlled trials (RCTs) (Ghanizadeh et al., 2014; Ichikawa et al., 2017; McDougle et al., 2000; Nagaraj et al., 2006; Pandina et al., 2007). Risperidone and aripiprazole are antipsychotic medication approved in the USA by the Food and Drug Administration (FDA) for the treatment of irritability associated with autistic disorder in children (Owen et al., 2009; Shea et al., 2004). In the UK, risperidone has been approved for the management of behavioural disturbance in children and adolescents associated with ASD and conduct disorder (European Medicines Agency, 2007). However, many other antipsychotic medications are prescribed. A recent study on the psychotropic medication prescribing for patients with ASD using the UK primary care database found that antipsychotics was prescribed to approximately $12.4 \%$ of the treated cohort; $50.7 \%$ of the issued prescriptions were for risperidone and $49.3 \%$ for other antipsychotics (Alfageh et al., 2020). 
Several published papers have described the adverse events reported with the use of these agents. Metabolic adverse events, such as weight gain and hyperprolactinemia, have been reported frequently (Almandil et al., 2013). Extrapyramidal symptoms (EPS), such as tardive dyskinesia (TD), have also been reported, particularly with the typical antipsychotics (Caroff et al., 2002; Posey et al., 2008).

Seizures are serious central nervous system (CNS) adverse events. Both first-generation and second-generation antipsychotics can lower the seizure threshold, increasing the chances of seizure occurrence (Hedges et al., 2003a, 2003b; Lertxundi et al., 2013). However, as highlighted in a previous review (Hedges et al., 2003a, $2003 \mathrm{~b}$ ), most of the literature in this area consists of case reports. There is a lack of well-designed analytical studies of the risk of seizures with antipsychotic medication, particularly in populations with ASD.

The situation is complicated by the fact that ASD itself and intellectual disability, which is common in people with ASD, are risk factors for seizures (Canitano, 2007; Volkmar \& Nelson, 1990). The aim of this study was to determine the risk of incident seizure in a population of patients with ASD.

\section{Methods}

\section{Data Source}

IQVIA Medical Research Data (IMRD-UK) (formerly known as THIN) was the data source. This is a primary care electronic medical records database from the early 1990s to the present day. It covers approximately $6 \%$ of the UK population and has more than 10.5 million patients, 3.7 million of them are actively registered patients. Data from IMRD-UK are generalisable to the UK for demographic structures and major condition prevalence (Blak et al., 2011). This database is validated as a source of data for use in pharmacoepidemiological research (Lewis et al., 2007) and has been utilised previously for the study of medication in ASD (Alfageh et al., 2020; Murray et al., 2014).

\section{Ethical Approval}

Ethical approval for this fully anonymised study was obtained from the Scientific Review Committee (SRC), which was established to review research using the IMRDUK database (ref: 18THIN044).

\section{Study Design}

\section{Cohort}

Two study designs were used in this retrospective study namely the cohort and the self-controlled case series (SCCS) design. In the cohort design, the risk of seizure in a population with ASD exposed to antipsychotics was compared to those who were on other psychotropic medication comprising antidepressants, stimulants or nonbenzodiazepine hypnotics and anxiolytics. The exposure group was comprised of patients who had been prescribed antipsychotics after the diagnosis of ASD. Patients who had a record of epilepsy or seizure before the index date were excluded from the analysis. Some patients were exposed to both antipsychotics and other psychotropic medication. The follow-up time of patients using 'other psychotropic medication' was censored once they received a prescription for an antipsychotic agent. Another followup period for them started on the first day of the antipsychotics prescription (Fig. 1a).

In this cohort, patients were followed from the date of the first prescription of the study medication that followed the ASD diagnosis. This date was considered to be the index date for each patient. In the primary analysis, the end of the follow-up date was defined as the earliest of the following: occurrence of the outcome date, the medication of interest had been switched or discontinued, death, date of last data collection or the end date of the study. Figure 1a illustrates the follow-up period for each observation during the cohort primary analysis.

\section{SCCS}

An SCCS analysis was performed to estimate the incidence rate ratio (IRR) of seizure during predefined risk windows according to the exposure period compared to the remaining observation periods (non-exposure; baseline period) within each patient (see Fig. 1b). This study design overcomes the potential effect of time-fixed confounders such as genetic effects, as the comparison is carried out by using each individual as their own control ("self-controlled") instead of comparing different groups of participants (Whitaker et al., 2006). In this SCCS analysis, the exposure was antipsychotic medication. Another SCCS analysis was conducted using other psychotropics specified in the cohort study (see appendix 1).

Seizure can be a recurrent event and the first seizure could be followed by other seizure events; therefore, only the first (incident) seizure was included in the analysis to avoid the violation of SCCS assumptions. A pre-exposure 


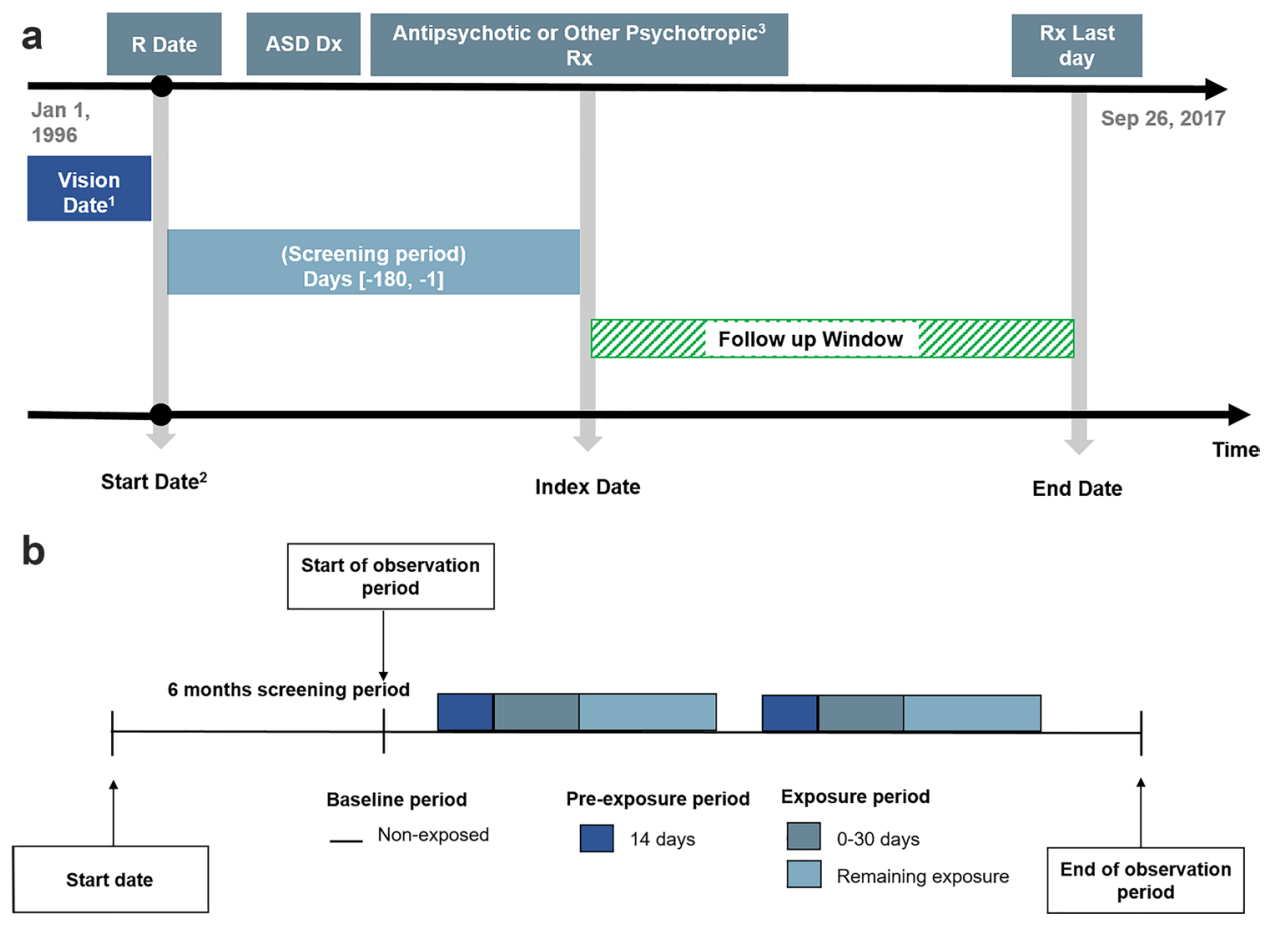

Fig. 1 a Cohort analysis observation follow-up period. ${ }^{1}$ Vision Date is the date of implementing Vision software which is a computerised clinical management system used by the general practices to record patient information. ${ }^{2}$ Start Date is the latest of either the date of the individual patient registration at the general practice, Vision date, second birthday or the date of the study start Jan 1, 1996. ${ }^{3}$ Psychotropic medication classes included were: antidepressants, stimulants

period was added to the risk period to consider the likelihood that the occurrence of seizure may affect the probability of antipsychotic treatment. During data extraction for the SCCS analysis, the data of the patients who had both an incident seizure and exposure to antipsychotics were extracted.

In this SCCS analysis, the observation start date was defined as the first day after the end of the six-month screening period. The ASD diagnosis date was recorded before or after the observation start, provided that it preceded or was on the date of first medication exposure. For each participant, the observation period was divided into the baseline period, including periods before and after medication exposure, and the exposure period. The exposure period was further divided into three risk windows: 14 days before medication exposure (the pre-exposure period); the first 30 days of medication exposure, and the subsequent medication exposure. Some participants had multiple intermittent medication exposures within their observation time: each continuous exposure was divided into three distinct risk windows. Figure $1 \mathrm{~b}$ illustrates the observation period timeline for each participant during the SCCS analysis. and non-benzodiazepine hypnotics and anxiolytics. ${ }^{4}$ The follow-up time of patients using 'other psychotropic medication' was censored once they received a prescription for an antipsychotic agent. An another follow-up period for them started on the first day of the antipsychotics prescription. $R$ Date date of patient's registration in the GP, $A S D D x$ autism spectrum disorder diagnosis, $R x$ drug prescription. b SCCS observation period

\section{Participants, Exposure and Outcomes}

Within the UK, the National Institute for Health and Care Excellence (NICE) guidelines follow the International Classification of Diseases, Tenth Revision (ICD-10) and the Diagnostic and Statistical Manual of Mental Disorders, Fifth Revision (DSM-5) criteria for ASD diagnoses(NICE, 2011). In the UK primary care databases, clinical information such as symptoms and diagnoses is recorded as coded data using Read codes. A medical dictionary for Read codes is available for researchers to develop a comprehensive set of conditionspecific codes (code lists) which can be used to extract data that helps to identify cases or covariates of interest. Diagnostic Read codes were used to identify the patients in any age equal to or above two years with the first-recorded diagnosis of ASD between 1st of January 1996 to 26th September 2017 (see appendix 2). The start date of each patient was defined as the latest of the following: the date of the patient's registration at the general practice, the date that the general practice began using Vision software (a clinical management system) or their second birthday. Patients were included if they received at least one prescription of the study medications, which included the following classes of psychotropic 
medication: antipsychotics, antidepressants, stimulants and non-benzodiazepine hypnotics and anxiolytics. Medication lists for each class were obtained from the British National Formulary Chapter 4 (see appendix 3). Anti-seizure medications (ASMs), (formerly known as antiepileptic drugs) and also benzodiazepines that are not necessarily listed as ASMs were not included because of the likely effect on the outcome of interest (seizures). Drug codes of the preceding psychotropics were extracted to identify medication exposure. Patients were considered eligible for inclusion in the study only if they had a screening period of at least six months available from their start date to the date of first prescription that followed the ASD diagnosis (except for those patients whose start date equalled their second birthday, for whom no screening period was required).

The outcome in this study was incident seizure. The seizure diagnosis was identified by the read codes list obtained from a previous study on incident seizure using a UK general practice database(Chui et al., 2016) (see appendix 4).

\section{Statistical Analyses (Cohort Study)}

\section{Propensity Score Fine-Stratification Weighting}

Propensity score (PS) fine-stratification weighting with 50 strata was applied to adjust for potential confounders. Unlike conventional PS weighting such as Inverse probability of treatment weighting IPTW, PS fine-stratification does not depend directly on PS to calculate the observation weight; instead it uses PS to create fine strata. In each stratum, weights for the exposed group are set to 1 and un-exposed patients are reweighted based on the number of exposed patients residing within their stratum; Therefore, extreme weights resulting from PS that are close to 0 or 1 are unlikely (Desai \& Franklin, 2019).

A number of potential confounders were included in the PS model (see appendix 5). Standardised mean differences (SMD) were used to examine the balance of covariates between the exposure groups (Table 1). SMD greater than 0.1 indicates evidence of imbalance between treated and control groups (Zhang et al., 2019). Hazard ratios (HR) of incident seizure were estimated using a Cox proportional hazard model. To adjust for potential clustering effect of patients contributed to both antipsychotics and other psychotropic groups, robust standard error was applied (Man et al., 2017).

\section{Sensitivity Analyses (Cohort Study)}

Sensitivity analyses were applied to examine the validity of the primary analysis. The purpose of these analyses was to investigate the effect of different follow-up periods on the resulting HR. In the sensitivity analyses, the definition of the end of follow-up date was changed to the following: (1) the earliest of: occurrence of the outcome date, death, the patient left the practice or the end date of the study; (2) the earliest of: occurrence of the outcome date, death, the patient left the practice or the end date of the study, 90 days after the first continuous medication exposure (grace period). The grace period was added to allow for the residual effect of the medication or the possibility of persistence administration form a residual supply of medication that had resulted from patient non-adherence.

\section{Statistical Analyses (SCCS)}

A semi-parametric SCCS model was applied to estimate the risk by comparing the risk of incident seizure in different risk windows to the baseline period. In this model, the age effect does not need to be pre-specified (Farrington \& Whitaker, 2006). Conditional Poisson regression was fitted to estimate the IRR, with $95 \%$ CIs.

\section{Sensitivity Analyses (SCCS)}

In SCCS, if the occurrence of the outcome leads to the censoring of the observation, this will fail the assumption. A seizure episode could be serious and lead to death (although this would be a very unlikely event) which, subsequently, would end the observation. Although this would be an exceptionally rare event, we conducted a sensitivity analysis by excluding patients who had died during the study period.

An additional SCCS analysis was carried using a negative control outcome: a negative control outcome is a tool that is commonly applied in observational studies to examine the validity of the causal inferences (Lipsitch et al., 2010). It helps to detect selection and measurement bias in epidemiological studies (Arnold et al., 2016). The concept of this approach relies on looking for an association that cannot plausibly be hypothesised. The negative control outcome must share a common source of correlated measurement error with the true outcome (Arnold et al., 2016). Otitis media is an acute recurrent event; the occurrence of this event has never been linked with the use of antipsychotic medication. Therefore, it has been selected as the negative control outcome to validate the causal 
Table 1 Characteristics baseline for the cohort study

\begin{tabular}{|c|c|c|c|c|c|c|}
\hline \multirow[t]{2}{*}{ Characteristic, no (\%) } & \multicolumn{2}{|l|}{ Crude } & \multirow[t]{2}{*}{ SMD } & \multicolumn{2}{|l|}{ Weighted } & \multirow[t]{2}{*}{ SMD } \\
\hline & Antipsychotic & Other psychotropic ${ }^{\mathrm{a}}$ & & Antipsychotic & Other psychotropic ${ }^{a}$ & \\
\hline Age, mean(SD) & $25.7(14)$ & $18.1(12.2)$ & 0.582 & $25.7(14)$ & $26.7(17.5)$ & -0.061 \\
\hline \multicolumn{7}{|l|}{ Gender } \\
\hline Female & $906(23.1)$ & $2391(23.7)$ & -0.014 & $906(23.1)$ & $2353(23.4)$ & -0.006 \\
\hline Male & $3017(76.9)$ & $7695(76.3)$ & 0.014 & $3011(76.9)$ & $7712(76.6)$ & 0.006 \\
\hline \multicolumn{7}{|l|}{ Smoking and alcohol status } \\
\hline Current smoker & $553(14.1)$ & $957(9.5)$ & 0.143 & $552(14.1)$ & $1508(15)$ & -0.025 \\
\hline Ex-smoker & $265(6.8)$ & $659(6.5)$ & 0.009 & $265(6.8)$ & $832(8.3)$ & -0.057 \\
\hline Problematic drinker & $203(5.2)$ & $362(3.6)$ & 0.078 & $203(5.2)$ & $605(6)$ & -0.036 \\
\hline \multicolumn{7}{|l|}{ Comorbidities } \\
\hline Neuropsychiatric comorbidities $(+)$ & $3346(85.3)$ & $7554(74.9)$ & 0.263 & $3340(85.3)$ & $8635(85.8)$ & -0.015 \\
\hline Diabetes $(+)$ & $94(2.4)$ & $114(1.1)$ & 0.096 & $94(2.4)$ & $276(2.7)$ & -0.022 \\
\hline Hypertension $(+)$ & $1079(27.5)$ & $2860(28.4)$ & -0.019 & $1079(27.5)$ & $3088(30.7)$ & -0.069 \\
\hline Stroke $(+)$ & $8(0.2)$ & $10(0.1)$ & 0.027 & $8(0.2)$ & $21(0.2)$ & 0 \\
\hline \multicolumn{7}{|l|}{ Medication use } \\
\hline Current user of Antidiabetic medication ${ }^{\mathrm{b}}$ & $30(0.8)$ & $20(0.2)$ & 0.082 & $30(0.8)$ & $109(1.1)$ & -0.033 \\
\hline Ex-user of Antidiabetic medication ${ }^{b}$ & $9(0.2)$ & $9(0.1)$ & 0.035 & $9(0.2)$ & $15(0.2)$ & 0.018 \\
\hline Current user of Antihistamine & $804(20.5)$ & $1761(17.5)$ & 0.077 & $802(20.5)$ & $2084(20.7)$ & -0.006 \\
\hline Ex-user of Antihistamine & $698(17.8)$ & $2245(22.3)$ & -0.112 & $698(17.8)$ & $1861(18.5)$ & -0.017 \\
\hline Current user of Tramadol & $27(0.7)$ & $88(0.9)$ & -0.021 & $27(0.7)$ & $82(0.8)$ & -0.014 \\
\hline Ex-user of Tramadol & $39(1)$ & $115(1.1)$ & -0.014 & $39(1)$ & $137(1.4)$ & -0.034 \\
\hline Current user of NSAID & 454 (11.6) & $1192(11.8)$ & -0.008 & $454(11.6)$ & $1247(12.4)$ & -0.025 \\
\hline Ex- user of NSAID & $617(15.7)$ & $2039(20.2)$ & -0.117 & $617(15.8)$ & $1629(16.2)$ & -0.012 \\
\hline Current user of Cytostatic & $14(0.4)$ & $19(0.2)$ & 0.032 & $14(0.4)$ & $34(0.3)$ & 0.003 \\
\hline Ex-user of Cytostatic & $6(0.2)$ & $18(0.2)$ & -0.006 & $6(0.2)$ & $15(0.2)$ & 0 \\
\hline Current user of Immunomodulator & $7(0.2)$ & $22(0.2)$ & -0.009 & $7(0.2)$ & $18(0.2)$ & 0 \\
\hline Ex-user of Immunomodulators & $6(0.2)$ & $11(0.1)$ & 0.012 & $6(0.2)$ & $38(0.4)$ & -0.043 \\
\hline \multicolumn{7}{|l|}{ ASM } \\
\hline Current user of ASM & $400(10.2)$ & $196(1.9)$ & 0.351 & $394(10.1)$ & $884(8.8)$ & 0.044 \\
\hline Ex-user of ASM & $20(0.5)$ & $18(0.2)$ & 0.057 & $20(0.5)$ & $44(0.4)$ & 0.01 \\
\hline Current user of Benzodiazepine & $451(11.5)$ & $272(2.7)$ & 0.348 & $446(11.4)$ & $1135(11.3)$ & 0.003 \\
\hline Ex-user of Benzodiazepine & $49(1.2)$ & $64(0.6)$ & 0.064 & $49(1.3)$ & $154(1.5)$ & -0.024 \\
\hline
\end{tabular}

$S M D$ standardised mean difference, $S D$ standard deviation, $N S A I D$ non-steroidal anti-inflammatory drug, ASMs anti-seizure medications ${ }^{\text {a }}$ Psychotropic medication classes included were: antidepressants, stimulants and non-benzodiazepine hypnotics and anxiolytics

${ }^{\mathrm{b}}$ Antidiabetic medication included: glutathione and sulfonylurea

interpretations of the antipsychotics and incident seizure SCCS. Patients with ASD who had been exposed to antipsychotics and developed otitis media were included in the analysis. Patients with otitis media records before the observation period were excluded.

\section{Results}

\section{Cohort}

During the study period, we identified a total of 16,282 patients with ASD who had received at least one medication prescription of the study medications. Of these, 3560 patients were excluded because of having less than six months screening period, their prescriptions date before the start date or after the end date or having history of epilepsy or seizure. A total of 12,722 patients met the inclusion criteria and were included in the cohort analysis. 1287 patients received psychotropics first then switched to antipsychotics and were included in both groups to have a total of 14,009 observations of patients in the analysis. Figure 2 is a flowchart illustrating the patient selection process. Three thousand nine hundred and twenty-three patients receiving antipsychotic prescriptions were identified and allocated to the exposed group: 10,086 patients were identified as being 
Fig. 2 Flow chart for patients' selection in the cohort study. ${ }^{1}$ In this step psychotropic medication classes included were: antipsychotics, antidepressants, anxiolytics, stimulants, and hypnotics, not including benzodiazepine. ${ }^{2}$ In this step psychotropic medication classes included were: antidepressants, stimulants and non-benzodiazepine hypnotics and anxiolytics

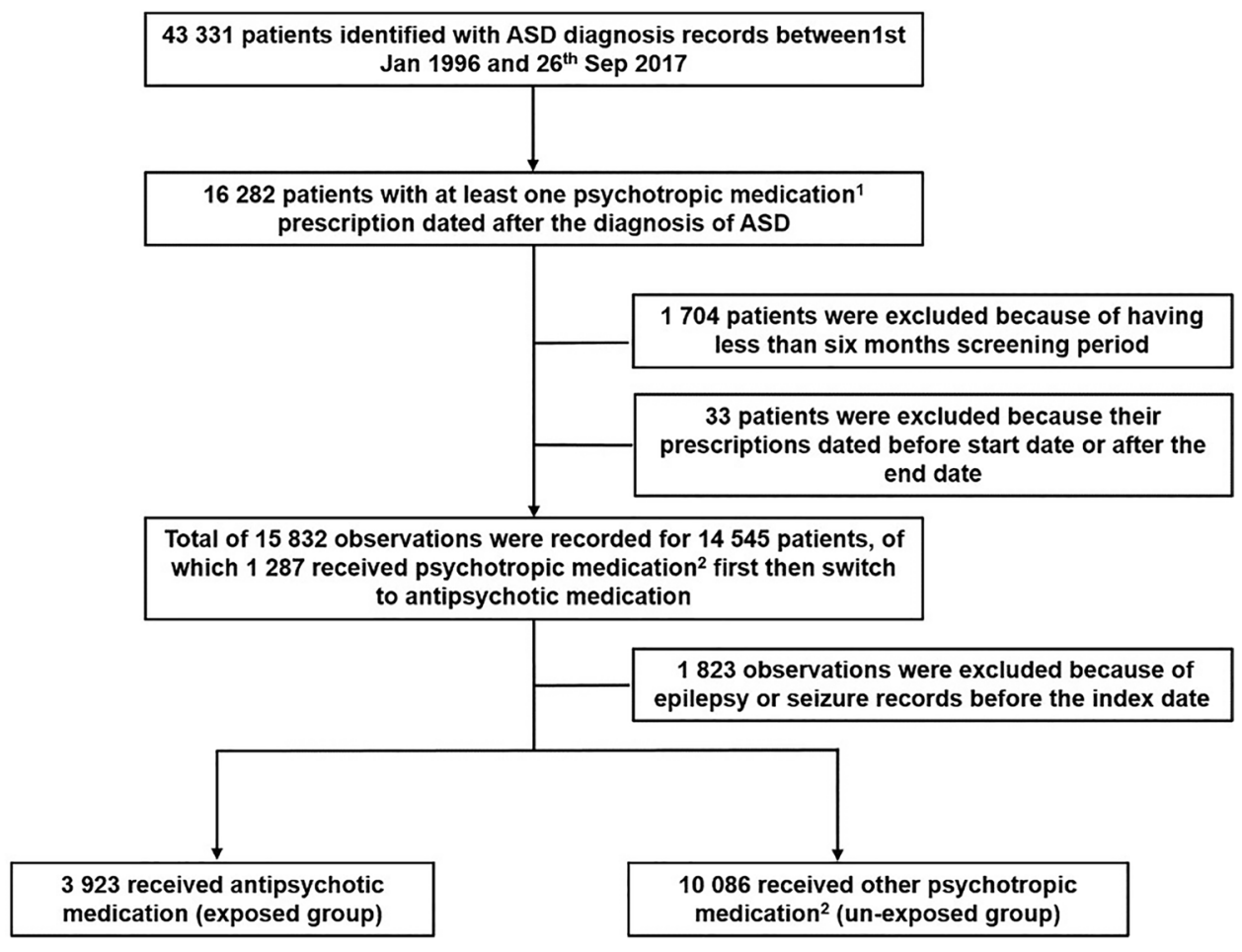

on other psychotropic medication and they were considered to be the unexposed group. The mean age of the participants at the index date was 25.7 years (SD 14.0) for the exposed group and the mean follow-up was 2.2 years (SD 2.6). For the unexposed group, the mean age was 18.1 years (SD 12.2) and the mean follow-up was 3.0 years (SD 3.4). The ratio of male to female patients in both the exposed and unexposed groups was approximately $3: 1$. In the PS-weighted model, all covariates were balanced between the two study groups, with SMD less than 0.1. Table 1 lists the crude and weighted baseline clinical characteristics of the exposed and unexposed groups at the index date, with standardised mean difference.

In the primary analysis, the incidence of seizure was 54 per 10,000 person-years (PY) in 3923 patients using antipsychotic medication, 36 per 10,000 PY in 10086 patients using other psychotropic medication. The PS-weighted HR of the incident seizure was $1.28,95 \%$ CI $0.74-2.19$, indicating no
Table 2 Results of the cohort analyses

\begin{tabular}{lllll}
\hline Group Patients (n) & Patient-years & $\begin{array}{l}\text { Incident } \\
\text { seizures }\end{array}$ & Crude HR (95\% CI) & Weighted HR (95\% CI)
\end{tabular}

(n)

Primary analysis

Follow up end by earlier of: outcome date, medication has been switched or discontinued, death, patient left practice or study end date

$\begin{array}{llllll}\text { Antipsychotic } & 3923 & 11,914 & 65 & 1.59(1.15-2.22) & 1.28(0.74-2.19) \\ \text { Psychotropic }^{\mathrm{a}} & 10,086 & 22,577 & 82 & 1 & 1\end{array}$

Sensitivity analyses

1. Follow up end by earlier of: outcome date, death, patient left practice or study end date

$\begin{array}{llllll}\text { Antipsychotic } & 3923 & 15,238 & 77 & 1.70(1.26-2.30) & 1.40(0.85-2.30) \\ \text { Psychotropic }^{\mathrm{a}} & 10,086 & 30,306 & 94 & 1 & 1\end{array}$

2. Follow up end by earlier of: outcome date, death, patient left practice, study end date or 90 days after first continuous exposure

\begin{tabular}{llllll} 
Antipsychotic & 3923 & 8988 & 52 & $1.80(1.23-2.65)$ & $1.36(0.72-2.57)$ \\
Psychotropic $^{\mathrm{a}}$ & 10,086 & 15,601 & 55 & 1 & 1 \\
\hline
\end{tabular}

${ }^{\text {a} P s y c h o t r o p i c ~ m e d i c a t i o n ~ c l a s s e s ~ i n c l u d e d ~ w e r e: ~ a n t i d e p r e s s a n t s, ~ s t i m u l a n t s ~ a n d ~ n o n-b e n z o d i a z e p i n e ~ h y p-~}$ notics and anxiolytics 
evidence of an increased risk of incident seizure associated with antipsychotic exposure compared to other psychotropics in the population with ASD. Sensitivity analyses results were consistent with the primary analysis; the HRs were $1.40,95 \%$ CI $0.85-2.30$ and 1.36 (0.72-2.57). Table 2 shows the results of the crude and weighted Cox proportional hazard model.

\section{SCCS}

One hundred and forty-nine patients were included in the SCCS analysis. The overall observation period was nearly 1529 patient-years. Almost $80 \%$ of the patients were males, with a mean age of 17.13 years (SD 14.59) at the start of observation. At the commencement of observation, the female patients were younger: the mean age of the females was 12.23 (SD 10.89). The average length of continuous antipsychotic prescriptions was 49 days, ranging from 1 to 2553 days. Table 3 provides details of the patient characteristics and the observation period.

In the primary SCCS analysis, using a semi-parametric model, the IRR of seizure for the first 30 days of antipsychotic exposure was 1.79 (95\% CI 0.97-3.30), which indicates no evidence of association between exposure to antipsychotics and increased risk of incident seizure. Two patients died during the study period and were excluded in

Table 3 Patients characteristics in the SCCS analyses

\begin{tabular}{|c|c|c|c|c|c|c|c|}
\hline \multirow[t]{2}{*}{ Characteristic } & \multirow[t]{2}{*}{ No. of patients (\%) } & \multirow{2}{*}{$\begin{array}{l}\text { Age at observation } \\
\text { start, mean (SD), Y }\end{array}$} & \multirow{2}{*}{$\begin{array}{l}\text { Length of prescrip- } \\
\text { tion, median (range) } \\
{[\mathrm{IQR}], \mathrm{d}}\end{array}$} & \multicolumn{2}{|c|}{ Risk period (exposure) } & \multicolumn{2}{|c|}{ Baseline period (no exposure) } \\
\hline & & & & $\begin{array}{l}\text { Incident } \\
\text { seizures, } \\
\text { No }\end{array}$ & $\begin{array}{l}\text { Total follow-up } \\
\text { time, patient- } \\
\text { years }\end{array}$ & $\begin{array}{l}\text { Incident } \\
\text { seizures, } \\
\text { No }\end{array}$ & $\begin{array}{l}\text { Total follow-up } \\
\text { time, patient-years }\end{array}$ \\
\hline \multicolumn{8}{|c|}{ 1. Risk of incident seizure associated with antipsychotic exposure } \\
\hline All & $149(100)$ & $16.15(14.03)$ & $49(1-2553)[25-78]$ & 61 & 479.4 & 88 & 1049.9 \\
\hline Male & $119(79.9)$ & $17.13(14.59)$ & $50(1-2553)[25-81]$ & 53 & 408.7 & 66 & 795 \\
\hline Female & $30(20.1)$ & $12.23(10.89)$ & $28(1-471)[15-56]$ & 8 & 70.7 & 22 & 254.9 \\
\hline \multicolumn{8}{|c|}{ 2. Risk of incident seizure associated with antipsychotic exposure (excluding patients died during study period) } \\
\hline All & $147(100)$ & $15.90(13.71)$ & & 60 & 469.2 & 87 & 1043.4 \\
\hline Male & $117(79.6)$ & $16.84(14.23)$ & $50(1-2553)[26-81]$ & 52 & 398.5 & 65 & 788.5 \\
\hline Female & $30(20.4)$ & $12.32(11.51)$ & $30(1-1841)[27-65]$ & 8 & 70.7 & 22 & 254.9 \\
\hline \multicolumn{8}{|c|}{ 3. Risk of otitis media associated with antipsychotic exposure (negative control) } \\
\hline All & $334(100)$ & $13.44(13.77)$ & $32(1-3763)[16-71]$ & 73 & 972.4 & 261 & 2691.6 \\
\hline Male & $250(74.8)$ & $12.32(13.26)$ & $42(1-3763)[21-74]$ & 54 & 737 & 196 & 2042.3 \\
\hline Female & $84(25.1)$ & $16.78(14.75)$ & $28(2-3549)[14-60]$ & 19 & 235.4 & 65 & 649.3 \\
\hline
\end{tabular}

Table 4 Results of semiparametric self-controlled case series (SCCS) analyses

\begin{tabular}{lccc}
\hline Risk window & $\begin{array}{l}\text { Incident sei- } \\
\text { zures (n) }\end{array}$ & Patient-years & Adjusted IRR (95\% CI) \\
\hline 1. Primary analysis, antipsychotic medication & exposure and risk of incident seizure \\
Baseline period & 88 & 1049.9 & - \\
14 days pre antipsychotic exposure & 9 & 57.5 & $1.66(0.74-3.71)$ \\
First 30 days of antipsychotic exposure & 26 & 156.3 & $1.79(0.97-3.30)$ \\
Subsequent antipsychotic exposure & 26 & 265.6 & $1.02(0.53-1.96)$ \\
2. Sensitivity analysis, excluding patients died within observation period & \\
Baseline period & 87 & 1043.4 & - \\
14 days pre antipsychotic exposure & 8 & 55.9 & $1.52(0.65-3.58)$ \\
First 30 days of antipsychotic exposure & 26 & 152.7 & $1.79(0.96-3.35)$ \\
Subsequent antipsychotic exposure & 26 & 260.6 & $1.08(0.56-2.11)$ \\
3. Negative outcome control, antipsychotic & medication exposure and risk of incident otitis media \\
Baseline period & 261 & 2691.6 & - \\
14 days pre first antipsychotic exposure & 8 & 119.5 & $0.74(0.32-1.73)$ \\
First 30 days of antipsychotic exposure & 23 & 306.1 & $0.77(0.42-1.39)$ \\
Subsequent antipsychotic exposure & 42 & 546.8 & $0.75(0.42-1.34)$ \\
\hline
\end{tabular}


the sensitivity analysis, the results of the sensitivity analysis were consistent with the primary analysis. During the three defined risk periods of the semi-parametric SCCS analysis for a negative outcome, the IRR indicated no evidence of an association between antipsychotic exposure and increased risk of otitis media. The results of the SCCS analyses are shown in Table 4.

\section{Discussion}

\section{Main Findings}

This research found no evidence of an association between antipsychotic treatment and an increased risk of seizure in individuals with ASD. The PS-weighted cohort results found no evidence of increased risk of an incident seizure associated with antipsychotic exposure compared with the use of other psychotropic medication 1.28 (0.74-2.19). The results of the SCCS were consistent with the cohort study. The incidence rate ratio of seizure event was 1.79 , 95\% CI 0.97-3.30 during the first month of antipsychotic exposure.

Although there are published reports about antipsychotics and associated risk of seizures, most of these are descriptive studies. Therefore, a causal relation between antipsychotics use and development of seizure has not been unequivocally confirmed, particularly in individuals with ASD (Górska et al., 2019; Grover et al., 2015; Hedges et al., 2003a, 2003b; Williams \& Park, 2015). It should be noted in the light of evidence that around $50 \%$ of the prescribed antipsychotics for individuals with ASD are not approved in the UK for use in this population, which may indicate an off-label medication prescribing (Alfageh et al., 2020).

The likelihood of the association between antipsychotics and seizures has been investigated in patients with schizophrenia, mood disorders and dementia. A nested case-control study conducted in the UK using the Clinical Practice Research Datalink (CPRD) found that the prescription of haloperidol, prochlorperazine or trifluoperazine was associated with an increased risk of seizures: adjusted odds ratio (OR) $2.51,95 \%$ CI $1.51-4.18 \mathrm{com}-$ pared with non-users (Bloechliger et al., 2015). However, the comparison was between antipsychotic users and nonusers without specifying if the comparison group was on other-psychotropic medication or not and considering the study design used, the estimated risk could be inflated (Schuemie et al., 2019). In our study, we didn't compare the risk of seizure between different antipsychotic medication. A study with data from the national health insurance research database (NHIRD) compared the risk of seizure among first and second-generation antipsychotics in patients diagnosed with schizophrenia and mood disorders (Wu et al., 2016). This study showed no evidence of a higher risk of seizure associated with first-generation antipsychotics than the second generation: HR 1.34, 95\% CI $0.99-1.81 ; \mathrm{p}=0.06$ (Wu et al., 2016). When compared to risperidone, clozapine HR 3.06, 95\% CI 1.40-6.71; thioridazine HR 2.90, 95\% CI 1.65-5.10; chlorprothixene HR 2.60, 95\% CI 1.04-6.49 and haloperidol HR 2.34, 95\% CI 1.48-3.71 all had a higher risk of antipsychoticrelated seizure, while aripiprazole had a potentially lower risk of seizure: HR $0.41,95 \%$ CI $0.17-1.00 ; p=0.05(\mathrm{Wu}$ et al., 2016). However, the results of the previous study could be affected by confounding by indication rather than reflecting the actual effect of the medication on the risk of seizure. In our cohort study, most of the prescriptions of antipsychotics were for second-generation antipsychotics (82.4\%) and $45 \%$ of the prescriptions were for risperidone. For patients included in the SCCS analysis, a higher percentage of the antipsychotics prescriptions were issued for risperidone (57.6\%). In this study, we have not taken account of medication dose. There is considerable evidence from the literature that, for medications that are associated with increased seizure risk, the risk is very much related to medication dose (Górska et al., 2019; Grover et al., 2015; Varma et al., 2011). Other reports have suggested that low-dose antipsychotic medication, as used to treat anxiety and/or behavioural problems in young people with ASD might not be associated with an increased risk of seizures but this leaves the possibility that higher antipsychotic doses, such as those used to treat psychosis or bipolar disorder might be associated with an increased seizure risk.

\section{Strengths and Limitations}

\section{Strengths}

To our knowledge, this is the first analytical study investigating the association between antipsychotic agents and incident seizure compared to other psychotropics in population with ASD. The source of the data used in this research is a large primary care database representative of the UK population. Two different study designs were applied; which allowed us to calculate the incidence rate of seizure associated with exposure to antipsychotics and to eliminate between-person variations.

The cohort study was used to estimate the HR of the incident seizure associated with antipsychotic exposure compared with other psychotropic medication. Both the number of ASD subjects identified in the number and eligible for our study (14,009 observations) were large; they were followed for an average of more than two years. The PS fine stratification model that was used adjusts the variability between the 
study groups. PS fine stratification is a newer approach of the standard PS weighting; this model provides smaller relative bias in estimates of cases of low exposure prevalence (Desai \& Franklin, 2019).

The SCCS design that followed this analysis overcomes the effect of time-fixed measured and unmeasured potential confounders between individuals as each participant acts as their own control (Petersen et al., 2016). As the comparison of the event rate is within-person, a smaller sample size number is needed to conduct such a study. In our research, the case definition was very specific and was applied to a limited number of individuals. This sample involved individuals with ASD being treated with antipsychotics and had an incident seizure. The results of the sensitivity analysis were similar to the primary analysis. This indicated that the seizure events did not lead to death, which would subsequently have ended the observation; thus, no violation of the SCCS assumptions occurred during our study. This was consistent with the findings of another SCCS study (not on psychotropic medication) which applied the SCCS extension approach to examine the effects of seizure on censoring the observation period (Chui et al., 2016).

\section{Limitations}

IMRD-UK is a primary care database; therefore, only medication prescriptions provided by primary care general practitioners are recorded. Other prescriptions, for example, medication prescribed in secondary care settings or hospital discharge medication are not recorded. Similarly, the seizure diagnosis records; there could have been seizure events in hospital emergency departments that were not linked to the patients' files in the general practice (GP). This could have led to an underestimate the number of cases. The results of this research apply only to individuals with ASD with no history of epilepsy or seizure, and to antipsychotics in general; the analysis as was not stratified by type of antipsychotic medication. As indicated in the discussion, we have not taken account of medication dose. There are indications from the literature that higher doses of psychotropic medications are more likely to precipitate seizures. In this study, dose stratified risk estimates could potentially result in biased findings affected by inadequate study power resulting from a limited sample size. This applies to the estimate of repeated seizures in the cohort design, while in the SCCS only incident seizure can be included to avoid the violation of the SCCS design assumptions. Therefore, these issues should be addressed further in future studies.

\section{Conclusion}

People with ASD are at greater risk of developing seizures, whether treated with antipsychotic medication or not. No evidence of an increased risk of incident seizures associated with antipsychotics treatment in comparison with other psychotropics in the study population with ASD was identified. Future carefully-conducted studies in individuals with ASD and a history of epilepsy or seizures are recommended.

Supplementary Information The online version contains supplementary material available at https://doi.org/10.1007/s10803-021-05208-0.

Acknowledgments This study was supported by a scholarship from the Saudi Arabian Ministry of Education represented by King Saud University.

Author Contributions All authors contributed to the study conception and design. The first draft of the manuscript was written by Basmah Alfageh and all authors commented on previous versions of the manuscript. All authors read and approved the final manuscript.

Funding No funding was received for conducting this study.

Data Availability No additional data are available for sharing.

\section{Declarations}

Conflict of interest The authors declare that they have no conflict of interest.

Ethical Approval Ethical approval for this fully anonymised study was obtained from the Scientific Review Committee (SRC), which was established to review research using the IMRD-UK database (Ref: 18THIN044).

Open Access This article is licensed under a Creative Commons Attribution 4.0 International License, which permits use, sharing, adaptation, distribution and reproduction in any medium or format, as long as you give appropriate credit to the original author(s) and the source, provide a link to the Creative Commons licence, and indicate if changes were made. The images or other third party material in this article are included in the article's Creative Commons licence, unless indicated otherwise in a credit line to the material. If material is not included in the article's Creative Commons licence and your intended use is not permitted by statutory regulation or exceeds the permitted use, you will need to obtain permission directly from the copyright holder. To view a copy of this licence, visit http://creativecommons.org/licenses/by/4.0/.

\section{References}

Alfageh, B. H., Man, K. K., Besag, F. M., Alhawassi, T. M., Wong, I. C., \& Brauer, R. (2020). Psychotropic medication prescribing 
for neuropsychiatric comorbidities in individuals diagnosed with autism spectrum disorder (ASD) in the UK. Journal of Autism and Developmental Disorders, 50(2), 625-633.

Almandil, N. B., Liu, Y., Murray, M. L., Besag, F. M., Aitchison, K. J., \& Wong, I. C. (2013). Weight gain and other metabolic adverse effects associated with atypical antipsychotic treatment of children and adolescents: A systematic review and meta-analysis. Paediatric Drugs, 15(2), 139-150. https://doi.org/10.1007/ s40272-013-0016-6

Arnold, B. F., Ercumen, A., Benjamin-Chung, J., \& Colford, J. M. J. (2016). Brief report: Negative controls to detect selection bias and measurement bias in epidemiologic studies. Epidemiology, 27(5), 637-641. https://doi.org/10.1097/ede.0000000000000504

Blak, B., Thompson, M., Dattani, H., \& Bourke, A. (2011). Generalisability of the health improvement network (THIN) database: Demographics, chronic disease prevalence and mortality rates. Journal of Innovation in Health Informatics, 19(4), 251-255.

Bloechliger, M., Rüegg, S., Jick, S. S., Meier, C. R., \& Bodmer, M. (2015). Antipsychotic drug use and the risk of seizures: Followup study with a nested case-control analysis. CNS Drugs, 29(7), 591-603. https://doi.org/10.1007/s40263-015-0262-y

Canitano, R. (2007). Epilepsy in autism spectrum disorders. European Child \& Adolescent Psychiatry, 16(1), 61-66.

Caroff, S. N., Mann, S. C., Campbell, E. C., \& Sullivan, K. A. (2002). Movement disorders associated with atypical antipsychotic drugs. The Journal of Clinical Psychiatry, 63, 12-19.

Chui, C. S., Chan, E. W., Wong, A. Y., Root, A., Douglas, I. J., \& Wong, I. C. (2016). Association between oral fluoroquinolones and seizures: A self-controlled case series study. Neurology, 86(18), 1708-1715.

Desai, R. J., \& Franklin, J. M. (2019). Alternative approaches for confounding adjustment in observational studies using weighting based on the propensity score: a primer for practitioners. $B M J$, $367,15657$.

European Medicines Agency. (2007). Assessment of the paediatric needs psychiatry. Europian Medicines Agency.

Farrington, C., \& Whitaker, H. (2006). Semiparametric analysis of case series data. Journal of the Royal Statistical Society, 55(5), 553-594.

Ghanizadeh, A., Sahraeizadeh, A., \& Berk, M. (2014). A head-to-head comparison of aripiprazole and risperidone for safety and treating autistic disorders, a randomized double blind clinical trial. Child Psychiatry and Human Development, 45(2), 185-192.

Górska, N., Słupski, J., \& Cubała, W. J. (2019). Antipsychotic drugs in epilepsy. Neurologia i Neurochirurgia Polska, 53(6), 408-412. https://doi.org/10.5603/PJNNS.a2019.0052

Grover, S., Hazari, N., Chakrabarti, S., \& Avasthi, A. (2015). Association of clozapine with seizures: A brief report involving 222 patients prescribed clozapine. East Asian Archives of Psychiatry, 25(2), 73-78.

Hedges, D., Jeppson, K., \& Whitehead, P. (2003a). Antipsychotic medication and seizures: A review. Drugs of Today, 39(7), 551-557.

Hedges, D., Jeppson, K., \& Whitehead, P. (2003b). Antipsychotic medication and seizures: A review. Drugs Today, 39(7), 551-557. https://doi.org/10.1358/dot.2003.39.7.799445

Hsia, Y., Wong, A. Y., Murphy, D. G., Simonoff, E., Buitelaar, J. K., \& Wong, I. C. (2014). Psychopharmacological prescriptions for people with autism spectrum disorder (ASD): A multinational study. Psychopharmacology (berl), 231(6), 999-1009.

Ichikawa, H., Mikami, K., Okada, T., Yamashita, Y., Ishizaki, Y., Tomoda, A., Ono, H., Usuki, C., \& Tadori, Y. (2017). Aripiprazole in the treatment of irritability in children and adolescents with autism spectrum disorder in Japan: A randomized, doubleblind, placebo-controlled study. Child Psychiatry and Human Development, 48(5), 796-806.
Ji, N. Y., \& Findling, R. L. (2015). An update on pharmacotherapy for autism spectrum disorder in children and adolescents. Current Opinion in Psychiatry, 28(2), 91-101. https://doi.org/10.1097/ yco.0000000000000132

Lertxundi, U., Hernandez, R., Medrano, J., Domingo-Echaburu, S., García, M., \& Aguirre, C. (2013). Antipsychotics and seizures: Higher risk with atypicals? Seizure, 22(2), 141-143.

Lewis, J. D., Schinnar, R., Bilker, W. B., Wang, X., \& Strom, B. L. (2007). Validation studies of the health improvement network (THIN) database for pharmacoepidemiology research. Pharmacoepidemiology and Drug Safety, 16(4), 393-401.

Lipsitch, M., Tchetgen, E. T., \& Cohen, T. (2010). Negative controls: A tool for detecting confounding and bias in observational studies. Epidemiology, 21(3), 383.

Man, K. K. C., Chan, E. W., Ip, P., Coghill, D., Simonoff, E., Chan, P. K. L., Lau, W. C., Schuemie, M. J., Sturkenboom, M. C., \& Wong, I. C. (2017). Prenatal antidepressant use and risk of attention-deficit/hyperactivity disorder in offspring: Population based cohort study. BMJ, 357, j2350. https://doi.org/10.1136/bmj.j2350

McDougle, C. J., Scahill, L., McCracken, J. T., Aman, M. G., Tierney, E., Arnold, L. E., Freeman, B. J., Martin, A., McGough, J. J., Cronin, P., \& Posey, D. J. (2000). Research units on pediatric psychopharmacology (RUPP) autism network: Background and rationale for an initial controlled study of risperidone. Child and Adolescent Psychiatric Clinics of North America, 9(1), 201-224.

McPartland, J., \& Volkmar, F. R. (2012). Autism and related disorders. Handbook of Clinical Neurology, 106, 407-418. https://doi.org/ 10.1016/b978-0-444-52002-9.00023-1

Murray, M. L., Hsia, Y., Glaser, K., Simonoff, E., Murphy, D. G., Asherson, P. J., Eklund, H., \& Wong, I. C. (2014). Pharmacological treatments prescribed to people with autism spectrum disorder (ASD) in primary health care. Psychopharmacology (berl), 231(6), 1011-1021.

Nagaraj, R., Singhi, P., \& Malhi, P. (2006). Risperidone in children with autism: Randomized, placebo-controlled, double-blind study. Journal of Child Neurology, 21(6), 450-455. https://doi.org/10. $1177 / 08830738060210060801$

NICE. (2011). Autism spectrum disorder in under 19s: Recognition, referral and diagnosis. National Institute for Health and Clinical Excellence.

Owen, R., Sikich, L., Marcus, R. N., Corey-Lisle, P., Manos, G., McQuade, R. D., Carson, W. H., \& Findling, R. L. (2009). Aripiprazole in the treatment of irritability in children and adolescents with autistic disorder. Pediatrics, 124(6), 1533-1540.

Pandina, G. J., Bossie, C. A., Youssef, E., Zhu, Y., \& Dunbar, F. (2007). Risperidone improves behavioral symptoms in children with autism in a randomized, double-blind, placebo-controlled trial. Journal of Autism and Developmental Disorders, 37(2), 367-373.

Petersen, I., Douglas, I., \& Whitaker, H. (2016). Self controlled case series methods: an alternative to standard epidemiological study designs. BMJ, 354, i4515.

Posey, D. J., Stigler, K. A., Erickson, C. A., \& McDougle, C. J. (2008). Antipsychotics in the treatment of autism. The Journal of Clinical Investigation, 118(1), 6-14.

Schuemie, M. J., Ryan, P. B., Man, K. K. C., Wong, I. C. K., Suchard, M. A., \& Hripcsak, G. (2019). A plea to stop using the casecontrol design in retrospective database studies. Statistics in Medicine, 38(22), 4199-4208. https://doi.org/10.1002/sim.8215

Shea, S., Turgay, A., Carroll, A., Schulz, M., Orlik, H., Smith, I., \& Dunbar, F. (2004). Risperidone in the treatment of disruptive behavioral symptoms in children with autistic and other pervasive developmental disorders. Pediatrics, 114(5), e634-e641.

Varma, S., Bishara, D., Besag, F. M., \& Taylor, D. (2011). Clozapine-related EEG changes and seizures: Dose and plasma-level 
relationships. Therapeutic Advances in Psychopharmacology, 1(2), 47-66. https://doi.org/10.1177/2045125311405566

Volkmar, F. R., \& Nelson, D. S. (1990). Seizure disorders in autism. Journal of the American Academy of Child \& Adolescent Psychiatry, 29(1), 127-129.

Whitaker, H. J., Farrington, C. P., Spiessens, B., \& Musonda, P. (2006). Tutorial in biostatistics: The self-controlled case series method. Statistics in Medicine, 25(10), 1768-1797. https://doi.org/10. 1002/sim.2302

Williams, A. M., \& Park, S. H. (2015). Seizure associated with clozapine: Incidence, etiology, and management. CNS Drugs, 29(2), 101-111. https://doi.org/10.1007/s40263-014-0222-y

Wong, A. Y., Hsia, Y., Chan, E. W., Murphy, D. G., Simonoff, E., Buitelaar, J. K., \& Wong, I. C. (2014). The variation of psychopharmacological prescription rates for people with autism spectrum disorder (ASD) in 30 countries. Autism Research, 7(5), 543-554.
Wu, C. S., Wang, S. C., Yeh, I. J., \& Liu, S. K. (2016). Comparative risk of seizure with use of first- and second-generation antipsychotics in patients with schizophrenia and mood disorders. Journal of Clinical Psychiatry, 77(5), e573-579. https://doi.org/10. 4088/JCP.15m09898

Zhang, Z., Kim, H. J., Lonjon, G., \& Zhu, Y. (2019). Balance diagnostics after propensity score matching. Ann Transl Med, 7(1), 16. https://doi.org/10.21037/atm.2018.12.10

Publisher's Note Springer Nature remains neutral with regard to jurisdictional claims in published maps and institutional affiliations. 